\title{
Cephalometric Norms of Erbil Kurdish Adults
}

\author{
Bootan A. Mustafa Chalabee*, Bayan A. Hassan \\ Department of Orthodontic, Faculty of Dentistry, Tishk International University, Erbil, Kurdistan Region, Iraq
}

\begin{abstract}
*Corresponding author:
Bootan A. Mustafa Chalabee, Department of Orthodontic,

Faculty of Dentistry, Tishk International University, Erbil, Kurdistan Region, Iraq.

E-mail: botankoye@hotmail. com
\end{abstract}

Received: 18 November 2019

Accepted: 24 February 2020

Published: 30 June 2020

\section{DOI}

10.25156/pt.v10n1y2020.pp130-134

\section{A B S T R A C T}

Ethical group might have differential skeletal forms, thus cephalometric analysis and orthodontic material have been developed for specific ethnic groups which might be different for Kurdish Ethics. Objectives: This study is to determine the cephalometric norms of an Erbil Kurdish population according to Steiner analysis, who attend to Tishk Hospital/Diagnosis Department Materials and Methods: In this cross-sectional study, 48 lateral cephalograms of adult orthodontic subjects between 20 and 29 years with normal occlusion, and with no previous orthodontic treatment were evaluated. Lateral cephalograms were traced and analyzed based on Steiner's cephalometric parameters. Data were analyzed using SPSS. Differences between Erbil Kurdish and Steiner's norms were analyzed using one-sample $t$-test $(P<0.05)$. Results: The SNA, ML-NSL (Mandibular Line to NS line), U1-NA (both angular and linear measurements), interincisal angle, L1-NB (angular only), Pog-NB, L1-Pog//NB, Ls-SL, and Li-SL values were significantly different between the Erbil Kurdish population and Steiner's norms $(P<0.05)$. No significant differences existed in Occl-SN (occlusal plane to SN) and L1-Nb (linear only), SNB, and ANB between the Erbil Kurdish population and the Steiner's norms $(P>0.05)$. Conclusions: Cephalometric norms for Erbil Kurdish adults are different from those of Steiner's norms. The norms obtained in our study can be used for orthodontic treatments and orthognathic surgeries in Erbil Kurdish population.

Keywords: Cephalometric norms; Erbil population; Kurdish ethnic; Lateral cephalograms; Steiner analysis

\section{INTRODUCTION}

Stable occlusal relationship, ideal masticatory function, and satisfactory esthetics are achieved by orthodontic treatment. Diagnosis, prevention, and correction of dental skeletal discrepancies are mostly in orthodontic treatment. Haring (2000) said to achieve a correct treatment plan, a true diagnosis is needed by the assessment of craniofacial morphology. History taking, clinical examination, and assessment of study models (dental casts), extraoral and intraoral radiograph, and photographs are the information for the orthodontic diagnosis and treatment plan basics. In orthodontic diagnosis and treatment plan, the main record has been lateral cephalometry. To find out the difference craniofacial anatomy, magnitude and direction of growth, treatment efficacy, and result comparison lateral cephalograms are one of the best records to depend on according to Dincer et al. (2013). Taki et al. (2009) said to achieve better facial balance and harmony Cephalometry is very essential and substantial diagnostic methodology to contrast the anatomical parameters of patient. McNamara (1984) concluded that following the introduction of cephalometry by Broadbent in 1931, few cephalometric analyses were created, among which the Downs, Steiner, Tweed, and Ricketts are the most popular and usually used ones by orthodontists. In Ferguson and Al Zain (2012) mentioned that European-American population has been the main source for the cephalometric analyses these values have been used on other ethnic groups for the evaluation of craniofacial patients, the equivalent is somewhat true about Steiner analysis. Hwang et al. (2002) argued that since cephalometric examination is essential for treatment planning of patients with reference value and so that cephalometric standard could be very different in various population; thus, one population cannot be used as standard reference for the others. Altemus (1960) acknowledged that it is all because individual of different races and ethnic have contrast in skeletal, soft-tissue, and dental. Alcalde et al. (1998), Craven (1958), and Hajighadimi et al. (1981), they all claimed that cephalometric norms very clear for each ethnic groups according to the previous, cephalometric norms of Caucasians have been noted that there are a big difference according to those of Indians (Atit et al., 2013), Tamils Nachiappan et al., 2015), Arabs (Hassan, 2006), Nepalese (Sharma, 2011), Turkish (Kilic et al., 2010), Japanese (Ioi et al., 2007), Chinese (Gu et al., 2011), Korean (Hwang et al., 2002), Pakistani (Khan et al., 2013), and African (Fadeju et al., 2013) populations. These distinctions ought to be considered in orthodontic finding and treatment planning just as in orthognathic surgery. Since it is clear that these norms are different from Caucasians it is important to find out cephalometric norms for every population. A 
few racial and ethnic groups dwell in various pieces of Iraq. The Kurds are an ethnic gathering in the Middle East mostly possessing a territory crossing adjoining portions of Southeastern Turkey, Western Iran, Northern Iraq, and Northern Syria. Gunter (2015) has claimed that they are assessed to number around 50 million. Cephalometric norms have been calculated in Iranians living in Isfahan (Azarbayejani et al., 2014), Mashhad (Imani et al. 2019), Babol (Imani et al., 2019), and Hamadan (Imani et al., 2019). However, to the best of our knowledge, cephalometric norms according to Steiner norms of Kurdish population living in North of Iraq/Erbil have not been previously studied, especially between the age of 20 and 29 years old.

\section{Objectives}

This study is to decide cephalometric norms in Erbil Kurdish population as indicated by the Steiner analysis. Cephalometric norms were compared and broadly used Caucasian norms.

\section{MATERIALS AND METHODS}

In this cross-sectional study, lateral cephalograms of 48 Erbil adult Kurds presenting to the Tishk Dental Hospital of Tishk International University in Erbil. The study protocol was approved in the Ethics Committee of Tishk International University of Erbil. The sample size was calculated according a previous study (Tenti, 1981). The inclusion criteria were: Age between 20 and 29 years, Kurdish ethnicity (mother, father, and grandparents must have been Kurds), facial symmetry, and normal soft-tissue profile without esthetic surgery, complete eruption of permanent teeth, and Angle Class I occlusion, minimal crowding, minimal spacing, no missing tooth except for third molars, no history of orthodontic treatment, no dental/facial prosthesis, no history of maxillofacial surgery, and history of facial trauma. Based on the inclusion criteria, 48 lateral cephalograms were taken from the diagnosis Department of Tishk Dental Hospital in Erbil including 24 males and 24 females. All cephalograms had been taken by the same dental X-ray unit (NewTom GiANO) [Figure 1], under similar conditions with teeth in centric occlusion. All cephalograms were traced by FACAD Software (Facad is a software for tracing and orthodontic treatment planning) [Figure 2].

Figure 3 shows all the linear and angular measurements. According to the methodology of Imani et al. (2019), each parameter was measured in duplicate and the mean value was recorded. The data were analyzed using SPSS version 23 (SPSS Inc., IL, USA). Descriptive statistics including the mean and standard deviation values were reported. The mean values of cephalometric parameters according

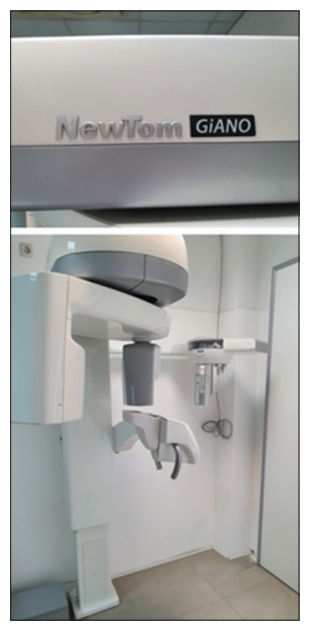

Figure 1: NewTom GiANO

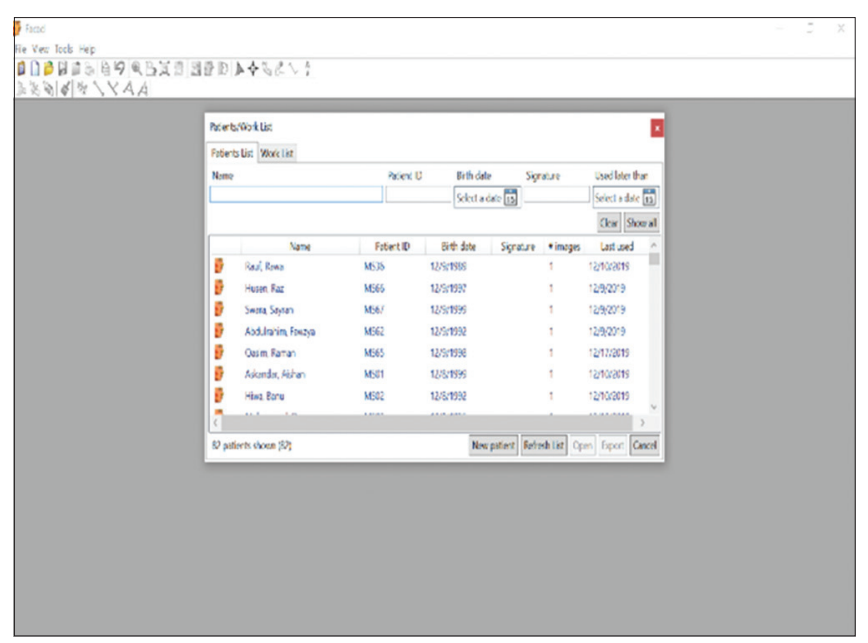

Figure 2: FACAD Software

to the Steiner analysis in the Erbil Kurdish population were compared with the Caucasian norms using onesample $t$-test. Independent $\mathrm{t}$-test was used to compare the cephalometric values between Erbil Kurdish males and females. $P<0.05$ was considered statistically significant.

\section{RESULTS}

Table 1 shows the comparison of cephalometric parameters according to the Steiner analysis in Erbil Kurdish population with the Caucasian norms. In Erbil Kurdish population, the mean values of ML-NSL (26.8 $\left.\pm 4.6^{\circ}, P<0.0001\right)$, interincisal $\left(121.7 \pm 5.9^{\circ}, P<\right.$ 0.0001), Pog-NB $(2.5 \pm 1.5 \mathrm{~mm}, P<0.0001)$, Ls-SL $(-4$ $\pm 2.2 \mathrm{~mm}, P<0.0001)$, and Li-SL $(-2.9 \pm 2.3 \mathrm{~mm}, P$ $<0.0001)$, were significantly smaller than the Caucasian norms. The mean SNA $\left(83.3 \pm 3.9^{\circ}, P=0.039\right)$, U1$\mathrm{NA}(4.5 \pm 1.2 \mathrm{~mm}, P=0.034), \mathrm{U} 1-\mathrm{NA}\left(26.1 \pm 4.8^{\circ}\right.$, $P<0.0001)$, L1-NB (29.4 $\left.\pm 4.5^{\circ}, P<0.0001\right)$, and $\mathrm{L} 1-\mathrm{Pog} / / \mathrm{NB}\left(1.3 \pm 2.4^{\circ}, P=0.0009\right)$ values in Erbil 


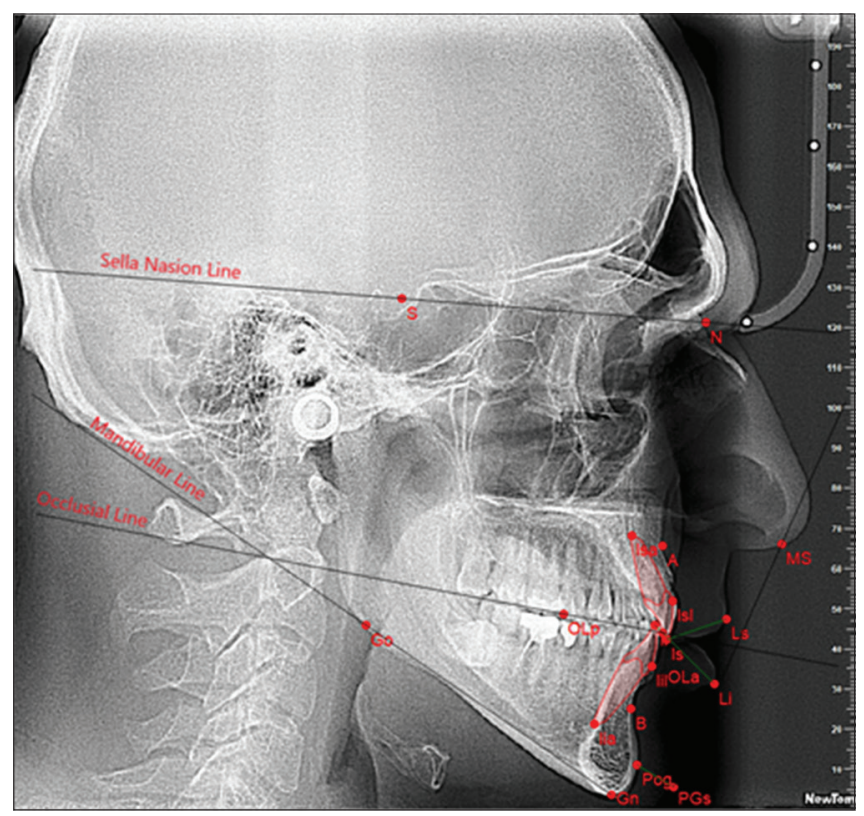

Figure 3: Steiner's analysis with the reference points

Table 1: A comparison of craniofacial values between the Erbil Kurdish sample and the Caucasian sample of the Steiner analysis

\begin{tabular}{lccc} 
Parameters & $\begin{array}{c}\text { Steiner, } \\
\text { std. } \\
\text { deviation }\end{array}$ & $\begin{array}{c}\text { Erbil Kurdish, } \\
\text { std. deviation }\end{array}$ & $\boldsymbol{P}$ value \\
\hline SNA & 82,2 & $83.3,3.9$ & 0.0392 \\
SNB & 80,2 & $80.7,3.4$ & 0.2301 \\
ANB & 2,2 & $2.6,2.2$ & 0.1572 \\
OL-NSL & 14 & $12.9,4.7$ & 0.1246 \\
ML-NSL & 32 & $26.8,4.6$ & $<0.0001$ \\
U1-NA & 4 & $4.4,1.2$ & 0.0346 \\
U1-NA & 22 & $26.1,4.8$ & $<0.0001$ \\
L1-NB & 4 & $3.9,1.3$ & 0.6823 \\
L1-NB & 25 & $29.4,4.5$ & $<0.0001$ \\
Interincisal & 130,1 & $121.7,5.9$ & $<0.0001$ \\
Pog-NB & 4 & $2.5,1.5$ & $<0.0001$ \\
L1-Pog//NB & 0 & $1.3,2.4$ & 0.0009 \\
Ls-SL & 0 & $-4.0,2.2$ & $<0.0001$ \\
Li-SL & 0 & $-2.9,2.3$ & $<0.0001$ \\
\hline
\end{tabular}

Kurdish population were significantly greater than the corresponding values in Caucasians. The SNB $\left(80.7 \pm 3.4^{\circ}\right.$, $P=0.230)$, ANB $\left(2.62 \pm 2.3^{\circ}, P=0.157\right)$, OL-NSL (12.9 $\left.\pm 4.7^{\circ}, P=0.124\right)$, and L1-NB $(3.9 \pm 1.3 \mathrm{~mm}, P=0.682)$ were not significantly different between Erbil Kurdish population and Caucasians.

Table 2 compares cephalometric parameters according to the Steiner analysis between Erbil Kurdish males and females. As shown in Table 2, Erbil Kurdish males and females were not significantly different in terms of all the values, and this is due to small sample for comparison between the females and males.

\section{DISCUSSION}

Cephalometric studies on non-Caucasian populations have indicated skeletal and dental differences in comparison with Caucasians. Therefore, cephalometric norms of one population cannot be used as reference for other populations. To obtain cephalometric norms of Erbil Kurdish population, we only included normal occlusion individuals with harmonic faces with no history of facial trauma or surgery. Our results showed that ML-NSL, interincisal, Pog-NB, Ls-SL, and Li-SL angles and distances were significantly smaller in Erbil Kurdish population compared to the Steiner norms, which indicates less vertical growth of mandible, more retruded incisors, less chin, and lip prominence. Erbil Kurdish population showed less vertical growth of mandible and more retruded lower incisal edge in contrast to Saudi Arabian populations. According to Al-Jasser (2005), these two parameters in the Saudi Arabian population are larger than the corresponding values in Caucasians and thus, Saudi Arabians have vertical mandibular growth and more protrusion of the lower incisal edge compared to the American-European populations. The ANB angle was insignificant in Erbil Kurdish population compared to Caucasians, which suggests a little difference compared to Caucasians, comparison of normal ANB angles between Erbil Kurdish population and Caucasians (2.6 $0^{\circ}$ vs. $2.0^{\circ}$, respectively). The ANB angle in Japanese population with normal occlusion was reported by Ioi et al. (2007) to be $2.5-4.5^{\circ}$ which was closer to Erbil kurds. Hussien et al. (2010) showed that the value of ANB angle in Palestinians $\left(2.7^{\circ}\right)$ was close to that in Caucasians. This value was reported to be $2.5^{\circ}$ in Saudi Arabians by Al-Jasser (2005). Comparison of the before-mentioned results shows that normal value of ANB is somewhat different in various races. The interincisal angle in Erbil Kurdish population was significantly smaller than the Steiner norm, which indicates dentoalveolar protrusion. This finding is in agreement with the findings of Al-Jasser (2005), who reported smaller interincisal angle in Saudi Arabians compared to Caucasians. In terms of Occl-SN angle, no significant difference was noted between Erbil Kurds and the norms reported by Steiner. Al-Jasser (2005) measured the Occl-SN angle in a Saudi Arabian population and showed that the value was close to that of Steiner norm, which was similar to our finding in this respect. Hussien et al. (2010) reported this value to be higher in Palestinians compared to Caucasians. Despite Occl-SN, GoGn-SN was significantly smaller in Erbil Kurdish population. Evaluation of Occl-SN and GoGn-SN altogether reveals that Erbil Kurds have a mild tendency to short face in comparison to Caucasians. The mean L1-NB angle of our samples $\left(29.4^{\circ} \pm 4.5^{\circ}\right)$ showed greater labial inclination of mandibular incisors in Erbil Kurds than in Caucasians. This parameter was 
Table 2: Comparison of cephalometric parameters according to the Steiner analysis between Erbil Kurdish males and females

\begin{tabular}{|c|c|c|c|c|c|c|}
\hline Parameters & Sex & $\mathrm{N}$ & Mean & Std. deviation & Std. error mean & $P$ value \\
\hline \multirow[t]{2}{*}{ SNA } & Males & 24 & 84.3292 & 4.11788 & 0.84056 & 0.0756 \\
\hline & Female & 24 & 82.3250 & 3.50605 & 0.71567 & \\
\hline \multirow[t]{2}{*}{ SNB } & Males & 24 & 81.2417 & 3.79690 & 0.77504 & 0.2638 \\
\hline & Female & 24 & 80.1500 & 3.04431 & 0.62142 & \\
\hline \multirow[t]{2}{*}{ ANB } & Males & 24 & 3.0667 & 2.23542 & 0.45630 & 0.1726 \\
\hline & Female & 24 & 2.1875 & 2.32273 & 0.47412 & \\
\hline \multirow[t]{2}{*}{ OL-NSL } & Males & 24 & 11.8458 & 4.75797 & 0.97122 & 0.1045 \\
\hline & Female & 24 & 14.0000 & 4.51394 & 0.92140 & \\
\hline \multirow[t]{2}{*}{ ML-NSL } & Males & 24 & 25.6750 & 5.58338 & 1.13970 & 0.0711 \\
\hline & Female & 24 & 28.0292 & 3.24164 & 0.66170 & \\
\hline \multirow[t]{2}{*}{ U1-NA } & Males & 24 & 4.4500 & 0.94547 & 0.19299 & 0.7807 \\
\hline & Female & 24 & 4.5417 & 1.51253 & 0.30874 & \\
\hline \multirow[t]{2}{*}{ U1-NA } & Males & 24 & 25.9083 & 3.82871 & 0.78153 & 0.7255 \\
\hline & Female & 24 & 26.4708 & 5.79351 & 1.18260 & \\
\hline \multirow[t]{2}{*}{ L1-NB } & Males & 24 & 4.2583 & 1.32498 & 0.27046 & 0.0685 \\
\hline & Female & 24 & 3.5417 & 1.32367 & 0.27019 & \\
\hline \multirow[t]{2}{*}{ L1-NB } & Males & 24 & 30.3583 & 5.08099 & 1.03715 & 0.1451 \\
\hline & Female & 24 & 28.4917 & 3.89648 & 0.79537 & \\
\hline \multirow[t]{2}{*}{ Interincisal } & Males & 24 & 120.6750 & 6.46699 & 1.32007 & 0.1977 \\
\hline & Female & 24 & 122.8708 & 5.27624 & 1.07701 & \\
\hline \multirow[t]{2}{*}{ Pog-NB } & Males & 24 & 2.4625 & 1.76581 & 0.36045 & 0.6585 \\
\hline & Female & 24 & 2.6833 & 1.40918 & 0.28765 & \\
\hline \multirow[t]{2}{*}{ Li-Pog//NB } & Males & 24 & 1.7875 & 2.62717 & 0.53627 & 0.2019 \\
\hline & Female & 24 & 0.8750 & 2.29730 & 0.46894 & \\
\hline \multirow[t]{2}{*}{ Ls-SL } & Males & 24 & -3.5333 & 2.61379 & 0.53354 & 0.1625 \\
\hline & Female & 24 & -4.4875 & 1.78114 & 0.36357 & \\
\hline \multirow[t]{2}{*}{ Li-SL } & Males & 24 & -2.5208 & 2.61251 & 0.53328 & 0.2470 \\
\hline & Female & 24 & -3.3375 & 2.12476 & 0.43372 & \\
\hline
\end{tabular}

almost similar to L1-NB angle in Saudi Arabians $\left(27.8^{\circ}\right)$ which was reported by Al-Jasser (2005). The mean L1-NB angle was $26.5^{\circ}$ in Palestinians (Hussien et al., 2010) while Anderson et al. (2000) reported this value to be $33.9^{\circ}$ in an African-American of 6-12 years old population. Based on the value of L1-NB distance, no significant difference existed between Erbil Kurdish population and Caucasians in terms of position of the lower incisors. In our study, no significant differences were noted in SNA and SNB angles between males and females, which were in line with the results of Hussien et al. (2010) on Palestinians. Gu et al. (2011) in their study on Chinese adults found no significant difference in SNA between males and females but males had a slightly larger SNB angle than females. In our study, the difference in ANB angle between males and females was not significant, which was in line with the results of Gu et al. (2011), Hussien et al. (2010) also reported similar ANB values between males and females. In Erbil Kurdish population, U1-NA distance was also insignificant between males and females, which was similar to the findings of Hussien et al. (2010). To the best of our knowledge, our study was the first to assess cephalometric norms according to the Steiner analysis in a Erbil Kurdish population and yielded values that can be used as cephalometric norms for orthodontic treatments and orthognathic surgeries in this population. Future studies with larger sample sizes are required on this population using other commonly used cephalometric analyses.

\section{CONCLUSION}

The outcomes demonstrated that some Steiner's cephalometric norms in Erbil Kurds are essentially not the same as Caucasians. There is no irrelevant contrast among males and females in the presented sample.

\section{AKNOWLEDGMENT}

The authors are thankful to Dr. Rebwar fadhil, the diagnosis assistant, and the staffs; and also to Dr. Duran the dean of dentistry faculty and Dr. Jwana my colleague, and Faculty of dentistry, international University of Tishk, for providing the necessary facilities for the preparation of the paper.

\section{CONFLICTS OF INTEREST}

The authors declare that there are no relevant financial interests about the submitted manuscript within the past 5 years and for the foreseeable future. 


\section{ETHICAL CONSIDERATIONS}

The research was carried out under conventional ethical considerations.

\section{FINANCIAL DISCLOSURE}

The authors declare that there are no relevant financial conflicts about the submitted manuscript within the past 5 years and for the foreseeable future.

\section{FUNDING/SUPPORT}

This research was funded by Researcher only.

\section{REFERENCES}

Alcalde, R. E., T. Jinno, M. A. Pogrel and T. Matsumura. 1998. Cephalometric norms in Japanese adults. J. Oral Maxillofac. Surg. 56(2): 129-134.

Al-Jasser, N. M. 2005. Cephalometric evaluation for Saudi population using the downs and Steiner analysis. J. Contemp. Dent. Pract. 6(2): $52-63$

Altemus, L. A. 1960. A comparison of cephalofacial relationships. Angle Orthod. 30(4): 223-240.

Anderson, A. A., A. C. Anderson, A. C. Hornbuckle and K. Hornbuckle. 2000. Biological derivation of a range of cephalometric norms for children of African American descent (after Steiner). Am. J. Orthod. Dentofacial Orthop. 118(1): 90-100.

Atit, M., M. Darda, S. Deshmukh, C. Naik, J. Rahalkar and V. Subramanian. 2013. Mean values of Steiner, tweed, Ricketts and Mcnamara analysis in Maratha ethnic population: A cephalometric study. APOS. 3(5): 137.

Azarbayejani, S., A. Omrani, A. Kalaantar-Motamedi, M. Abdellahi, V. Taalebi and F. Teimoori. 2014. Cephalometric norms for 6-17 year-old Iranians with normal occlusion and well-balanced faces. Dent. Res. J. 11(3): 327-335.

Craven, A. H. 1958. A radiographic cephalometric study of the central Australian aboriginal. Angle Orthod. 28(1): 12-35.

Dincer, B., E. Yetkiner, I. Aras, T. Attin, and R. Attin. 2013. Influence of lateral cephalometric radiographs on extraction decision in skeletal Class I patients. Head Face Med. 9(1): 36.

Fadeju, A. D., O. D. Otuyemi, P. I. Ngom and M. Newman-Nartey. 2013. A study of cephalometric soft tissue profile among adolescents from the three West African countries of Nigeria,
Ghana and Senegal. J. Orthod. 40(1): 53-61.

Ferguson, D. and AI Zain, T. 2012. Cephalometric characterization of an adult Emirati sample with Class I malocclusion. J. Orthod. Sci. 1(1): 11.

Gu, Y., J. A. McNamara, L. M. Sigler and T. Baccetti. 2010. Comparison of craniofacial characteristics of typical Chinese and Caucasian young adults. Eur. J. Orthod. 33(2): 205-211.

Gunter, M.M. 2015. Review of Kurdish awakening: Nation building in a fragmented homeland. Middle East Q. 22: 3.

Hajighadimi, M., H. L. Dougherty and F. Garakani. 1981. Cephalometric evaluation of Iranian children and its comparison with Tweed's and Steiner's standards. Am. J. Orthod. 79(2): 192-197.

Haring, J. I. 2000. Dental Radiography: Principles and Techniques. $2^{\text {nd }}$ ed. W.B. Saunders, Philadelphia, PA.

Hassan, A. H. 2006. Cephalometric norms for Saudi adults living in the Western region of Saudi Arabia. Angle Orthod. 76(1): 109-113.

Hussien, E., S. Al-Khateeb and M. A. Mowais. 2010. Palestinians norms of Steiner cephalometric analysis. World J. Orthod. 11(4): 5-9.

Hwang, H., W. Kim and J. McNamara. 2002. Ethnic differences in the soft tissue profile of Korean and European-American adults with normal occlusions and well-balanced faces. Angle Orthod. 72: $72-80$.

Imani, M. M., S. Farzaneh, A. Ghanbari and S. Arab. 2019. Cephalometric norms in an Iranian Kurdish population according to the Steiner analysis. Iran. J Orthod. 1: 63439.

loi, H., S. Nakata, A. Nakasima and A. L. Counts. 2007. Comparison of cephalometric norms between Japanese and Caucasian adults in antero-posterior and vertical dimension. Eur. J. Orthod. 29(5): 493-499.

Khan, T., I. Ahmed and Gul-e-Erum. 2013. Cephalometric measurments of a Pakistani adult sample according to Jarabak's analysis. JPMA. 63(11): 1345-1358.

Kilic, N., G. Catal and H. Oktay. 2010. McNamara norms for Turkish adolescents with balanced faces and normal occlusion. Aust. Orthod. J. 26(1): 33-37.

McNamara, J. A. 1984. A method of cephalometric evaluation. Am. J. Orthod. 86(6): 449-469.

Nachiappan, S., S. Tharanikumar, A. Chandran, P. Anusudha, G. Nandini and M. Balasubramaniam. 2015. A study to evaluate cephalometric hard tissue profile of Tamil population for orthognathic surgery. J. Pharm. Bioallied Sci. 7(6): 680.

Sharma, J. N. 2011. Steiner's cephalometric norms for the Nepalese population. J. Orthod. 38(1): 21-31.

Taki, A. A., F. Oguz and E. Abuhijleh. 2009. Facial soft tissue values in Persian adults with normal occlusion and well-balanced faces. Angle Orthod. 79(3): 491-494.

Tenti, F. V. 1981. Cephalometric analysis as a tool for treatment planning and evaluation. Eur. J. Orthod. 3(4): 241-245. 